\title{
Prospective Interventional Study to Quantify Barbed Suture Exposure at Vaginal Vault and Assess Post-0perative Risk
}

\author{
Divyesh V. Shukla1 ${ }^{*}$, Shilpi D. Shukla1 ${ }^{1}$, Amit Shah ${ }^{1}$, Sangita Patel ${ }^{2}$, Vaidehi Nene ${ }^{1}$ \\ ${ }^{1}$ Isha Hospital, Vadodara, India \\ ${ }^{2}$ Department of PSM, Medical College Baroda, Vadodara, India \\ Email: *divyeshshukla@yahoo.com
}

How to cite this paper: Shukla, D.V., Shukla, S.D., Shah, A., Patel, S. and Nene, V. (2020) Prospective Interventional Study to Quantify Barbed Suture Exposure at Vaginal Vault and Assess Post-Operative Risk. Open Journal of Obstetrics and Gynecology, 10, 855-865. https://doi.org/10.4236/ojog.2020.1070079

Received: May 25, 2020

Accepted: June 30, 2020

Published: July 3, 2020

Copyright () 2020 by author(s) and Scientific Research Publishing Inc. This work is licensed under the Creative Commons Attribution International License (CC BY 4.0).

http://creativecommons.org/licenses/by/4.0/

(c) (i) Open Access

\begin{abstract}
Background: The use of barbed suture in laparoscopic surgery is increasing ever since 2008. Published reports of use of unidirectional barbed suture for vaginal vault closure following total laparoscopic hysterectomy (TLH), indicates it is safe. Despite of this many reports of adhesions and bowel obstruction are reported. This complication was never assessed in relation to amount of suture exposure at vaginal vault. We thought of quantifying the barbed suture exposure at vaginal vault and assess the risk of post-operative complications. Objective: The objective was to quantify the exposure of barbed suture at vaginal vault by adopting a uniform technique of vault suturing and assessing postoperative risk related to adhesions at vaginal vault. Method: In 30 patients who underwent TLH, a uniform new technique of vaginal vault closure using barbed suture was used and the portion of suture exposed at vaginal vault was quantified. The patients were followed up for a period of 6 months to assess post-operative risk of adhesions at vault and sequalae. Result: Mean length of suture exposed was $2.64 \pm 1.65 \mathrm{~mm}$ only. Suture exposure at vaginal vault was seen in $23(76.67 \%)$ out of 30 patients. The suture was exposed on average at $1.57 \pm 1.20$ places at vaginal vault. Conclusion and Recommendations: The study with an accepted relative error of $5 \%$ quantifies barbed suture exposure at vaginal vault. We had adopted a uniform new method of vaginal vault suturing to study and to quantify barbed suture exposure. It was observed that very minimal portion of suture was exposed at vaginal vault. It was exposed at only a couple of places at vaginal vault. Thus, decreasing suture exposure at vaginal vault will reduce its exposure related risk.
\end{abstract}

\section{Keywords}

Barbed Suture, DS Suturing Technique, Suture Exposure, TLH, Vaginal Vault Closure 


\section{Introduction}

The use of barbed suture in laparoscopic surgery is increasing. First use of barbed suture for vaginal vault closure was suggested in 2008. Later on many authors recommended their use [1] [2] [3].

Unidirectional barbed suture is considered safe to be used for vaginal vault closure following total laparoscopic hysterectomy (TLH) [3] [4]. Despite of this, there are reports of soft tissue adhesion and small bowel obstruction with the use of barbed suture at vaginal vault [5] [6].

None of these studies had corelated suture exposure at vaginal vault and the risk of above complications. We thought it was necessary to quantify exposure of barbed suture at vaginal vault and corelate the post-operative risk of symptoms related to adhesions.

\section{Aims and Objectives}

1) To quantify the exposure of barbed suture at vaginal vault.

2) To adopt uniform technique of vault suturing aiming to reduce exposure.

3) To study short term and long-term complications related to use of barbed suture at vaginal vault.

\section{Material and Methods}

The study was approved by institutional ethical committee. This prospective study was performed to quantify the barbed suture exposure at vaginal vault and post-operative risk in patients undergoing TLH. The study period was of 7 months from $1^{\text {st }}$ Aug 2019 to $28^{\text {th }}$ Feb 2020. The study was carried out in multispeciality hospital at department of minimal access surgery, obstetrics and gynaecology.

Total 30 patients of TLH were recruited for the study after taking written consent. These patients were symptomatic for the pathology they were diagnosed. In these patients ether medical therapy was not indicted or the patient did not respond to medical treatment given to them in past. The demographic profile of the patients, associated co morbidities and indications of TLH based on clinical examination and trans-vaginal sonography were noted.

From the pilot study on 10 patients, we found suture exposure at vaginal vault was $77 \%$, so by keeping $20 \%$ allowable error and $\mathrm{p}=77$ and $\mathrm{q}=23$ and by applying $4 \mathrm{pq} / 12$ sample size comes 29.87 , so we took $30 \mathrm{TLH}$ patients after taking written informed consent (allowable error based on $\mathrm{p}=77$ ). Sample Size $=4 \times$ $77 \times 23 / 15.4 \times 15.4=29.87=30$.

Patients who had pre-operative complaints of nausea vomiting with abdominal pain were excluded.

The TLH or radical surgery was performed by using vessel sealer probe (Covidien made Maryland Laparoscopic sealer/divider 1937) and ultrasound ace probe (Harmonic ace, Ethicon Endo-Surgery). Uterine manipulator with cervical cup was used in TLH procedure with benign pathology. The final step of colpotomy 
was performed by using ultrasound probe, uterosacral ligament attachments were not cut. No bleeding was observed from cut vaginal margins after colpotomy. Vaginal vault suturing was initiated after suction evacuation in pelvis.

To quantify the barbed suture exposure a uniform new technique was used to suture vaginal vault in all. This technique followed principles of vaginal vault closure. The suturing method also aimed to minimize suture exposure at vaginal vault.

\section{Method of Suturing Vaginal Vault}

Ipsilateral suturing method using unidirectional barbed suture was performed using $\mathrm{KOH}$ Karl Storz type of needle holders. Barbed suture was Covidien made. (V-Loc180, $30 \mathrm{~cm}, 37 \mathrm{~mm} / 1 / 2$ circle taper point, 0-polydioxane). Suturing was attempted from right angle to left. $1^{\text {st }}$ suture was placed at right vaginal angle, posterior to anterior (included uterosacral ligament) needle than passes through the anchoring loop and the suture is kept as loose loop (Figure 1, Figure 2). Now $2^{\text {nd }}$ suture was taken (which included posterior peritoneum, pre rectal fascia posterior vaginal mucosa, anterior vaginal mucosa, pubocervico vesical fascia) through both vaginal walls.

Before pulling this suture to make it tight the assistant was asked to hold vaginal angle medially and now suture is pulled in such a way that the loose loop encircled right vaginal angle. This results in trans-cervical ligament to fix to right vaginal angle. The tension of pull on suture was put to the optimum extent, so no further tension was possible on the suture. This was obtained by placing opposite needle holder at the exit point of suture. This prevents soft tissue dragging. $3^{\text {rd }}$ and $4^{\text {th }}$ suture were placed in similar way and made tight (Figure 3 ). $5^{\text {th }}$ suture was kept loose, and a loop was made. The needle with suture was brought from lateral to medial from within the loop. The vaginal angle is hold medially by assistant before pulling the suture tight. This made the loop to encircle left vaginal angle. The desired tension is attained while pulling the suture. Final anchoring suture is taken before the suture is cut flushed to the surface of exit (Figure 4). The sutures placed at vault were about $8 \mathrm{~mm}$ to $10 \mathrm{~mm}$ apart and $5 \mathrm{~mm}$ from the edge (Figure 5, Figure 6). Additional sutures were placed as required depending on width of vaginal vault and requirement of haemostasis,

https://youtu.be/gcKc-aoN5jk.

The average length of suture used was noted.

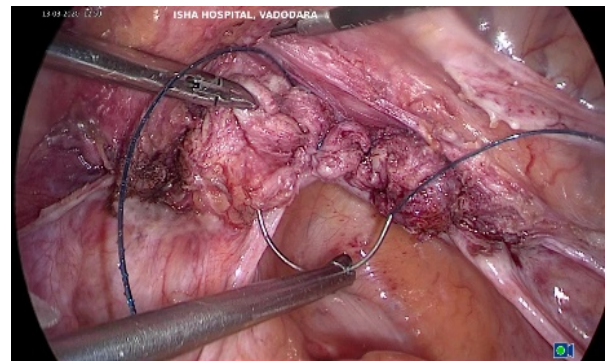

Figure 1. Suturing of left vaginal angle. 


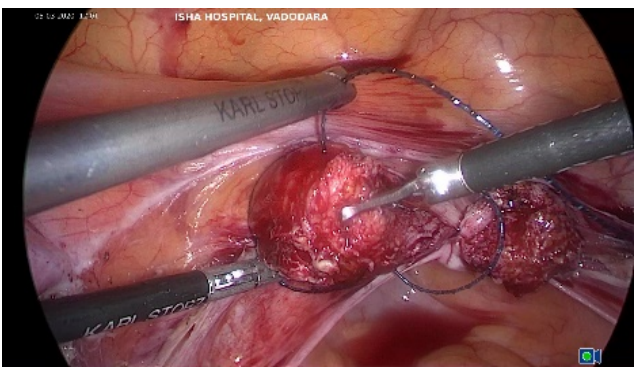

Figure 2. Suturing vaginal angle loop.

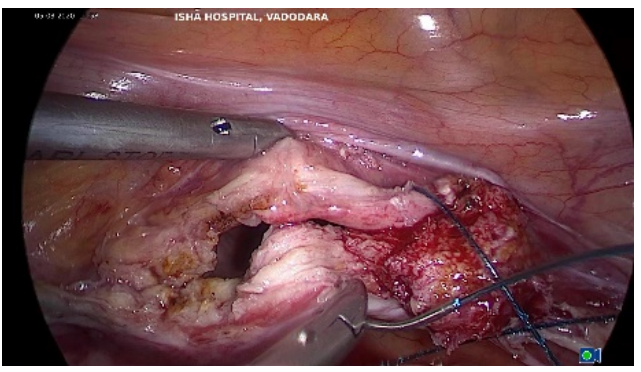

Figure 3. Suturing vagina.

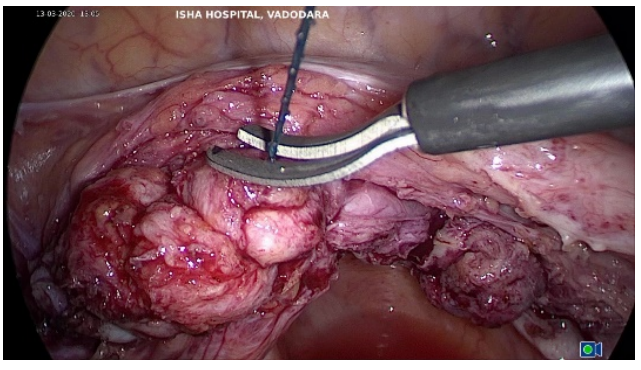

Figure 4. Suture cut flushed to surface.

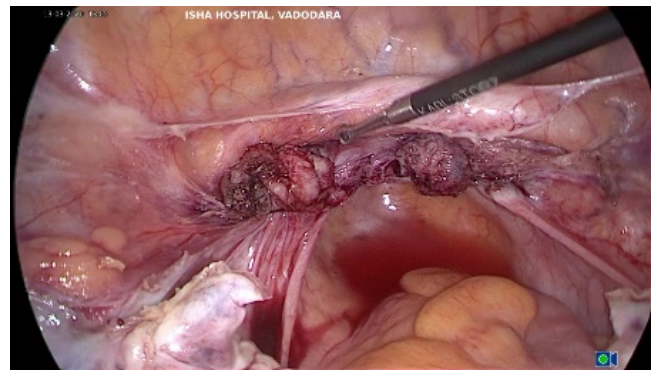

Figure 5. Vaginal vault suture line.

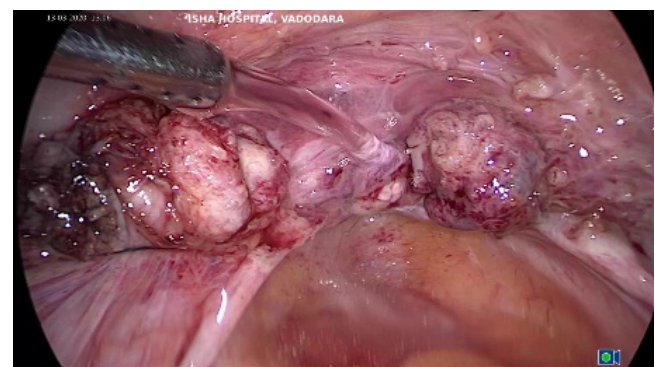

Figure 6. Vaginal vault suture line. 
HD video recording of complete surgery was done in all patients. Photographs were taken for all patients from these recording. The photograph which was used to quantify exposure of barbed suture at vaginal vault had suction cannula in the same reference plane of vault suture line. The photograph also had all sites of suture exposure evident.

Photographs were transferred to mobile phone. Prime Ruler application was used in android mobile phone (Developer Grymala Ltd.) to quantify suture exposure at vaginal vault. The methods followed to measure objects in the image were according to the instructions.

1) Reference object and measured object are in the same plane;

2) There are no distortions caused by perspective;

3) Size of the reference object is inputted correctly;

4) Limiters for the reference object are placed on the edges of the reference/measured object.

The width of suction cannula as reference object was measured as $5 \mathrm{~mm}$ in the same plane as vaginal vault (Figure 7, Figure 8). Taking this as reference the total length of suture exposed at vaginal vault was measured in mm (Figures 9-11). Number of times the suture was exposed and distance between the sutures was also noted (Figure 12, Figure 13). The application has a relative error of $5 \%$. These measurements and error reported were in accordance with the method described by the application developer. The information was obtained by E mail communication from the developer.

Per speculum examination was done immediately after surgery to look for suture exposure within vagina (Figure 14).

Bipolar coagulation was used if required at vaginal angles for haemostasis.

About $200 \mathrm{cc}$ of Ringer lactate was left in pelvis after thorough suction irrigation. Prophylactic broad-spectrum antibiotics and analgesics were prescribed to all patients for 7 days.

All patients were discharged after 24 hrs. of surgery. Schedule follow up was on day $5,8,3^{\text {rd }}$ wk., $8^{\text {th }}$ wk. and $6^{\text {th }}$ month. In follow up visit patients were asked about complaints of nausea, vomiting, abdominal pain, vaginal discharge, or bleeding. Vital signs were noted, abdominal palpation was done. Staple removal was performed on day 8 . At $8^{\text {th }}$ week and $6^{\text {th }}$ month follow up vaginal speculum examination was done over the above. The data was entered in Excel sheet and calculated with the use of statistical calculations.

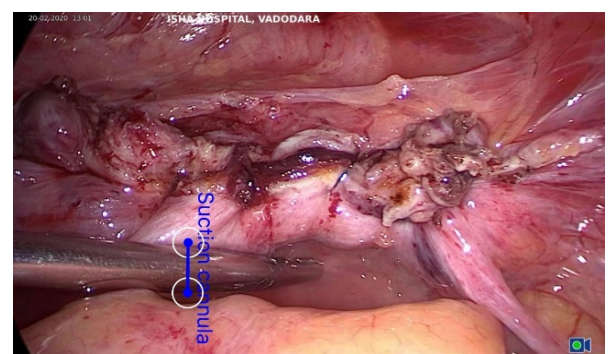

Figure 7. Suction cannula as reference measurement. 


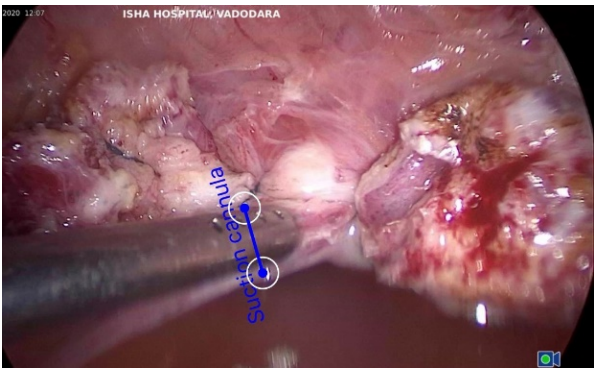

Figure 8. Suction cannula as reference measurement.

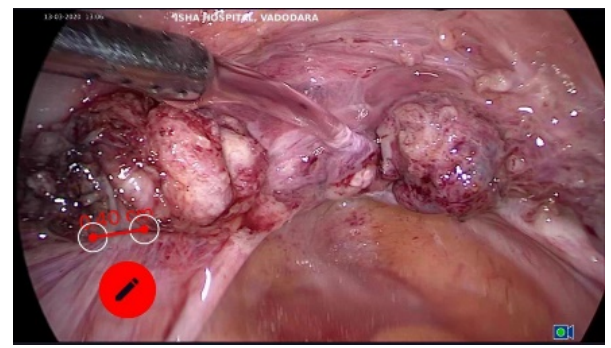

Figure 9. Suture exposure 1 place.

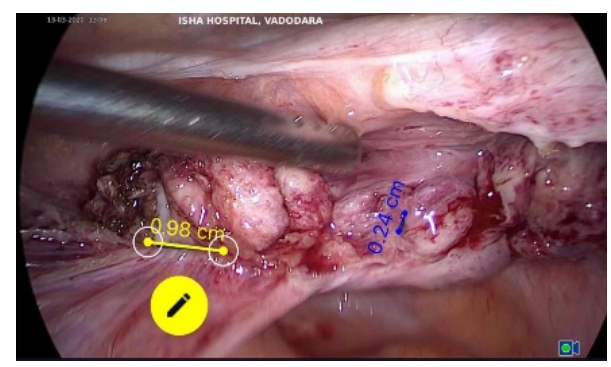

Figure 10. Suture exposure 2 places.

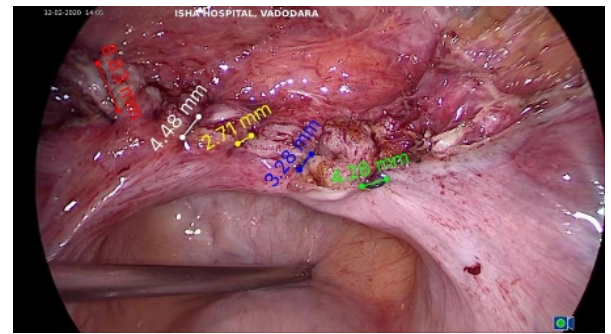

Figure 11. Suture exposure 5 places.

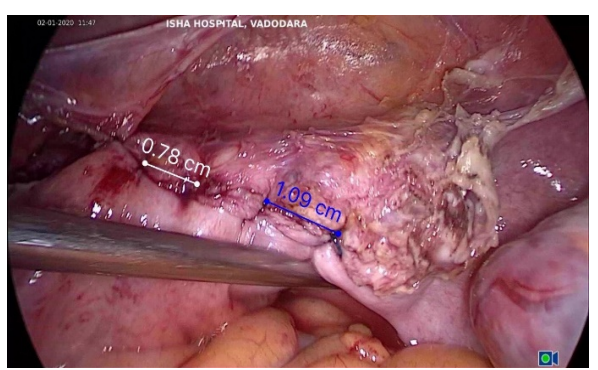

Figure 12. Distance between sutures. 


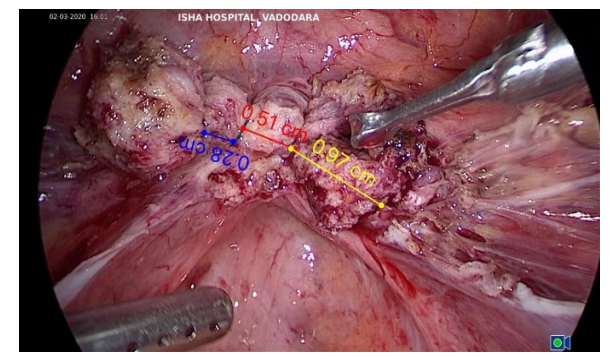

Figure 13. Distance between sutures.

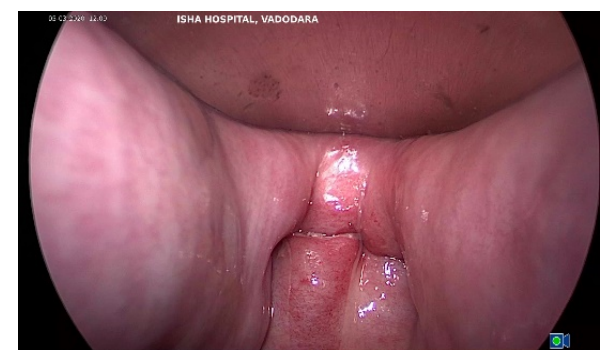

Figure 14. Per speculum examination immediate post-operative period, no suture exposure.

\section{Results}

Mean age and BMI of the patients in the study group was $47.91 \pm 8.96$ years and $28.14 \pm 3.92$ (Table 1$)$.

The indications for TLH were fibroid, endometriosis, adenomyosis as benign conditions in 29 (96.67\%) patients and only one patient had malignancy as $\mathrm{Ca}$ cervix (3.33\%). As the study group was predominantly beyond 45 years associated co-morbidities as hypertension, diabetes, hypothyroidism were seen in 20 (66.66\%) patients, 10 (33.33\%) patients had no co-morbidities (Table 1).

Mean length of suture exposed at vaginal vault was $2.64 \pm 1.65 \mathrm{~mm}$. In 23 (76.67\%) out of 30 patients suture exposure was seen. The suture was exposed on average at $1.57 \pm 1.20$ places at vaginal vault. This means in about $24 \%$ of patients suture exposure may not be evident with this technique used. The mean length of suture exposed was only $2.64 \mathrm{~mm}$ and was exposed only at one or 2 places at vaginal vault. In only 1 patient the suture was noticed exposed at 5 places. The total suture length used for suturing vaginal vault was about $17 \mathrm{~cm}$ on an average (Table 2 ).

Only $5(16.67 \%)$ patients required bipolar coagulation for haemostasis intraoperatively. These were the patients in which the vaginal angle loop was found to be loose. Entanglement of a barb sometimes may not achieve desired tightness. The uterine vessels were observed ligated at vaginal angles in $80 \%$ of the patients. This could be because of the surgical and suturing technique.

Per speculum examination in immediate post-operative time revealed suture exposure in $2(6.67 \%)$ patients. No suture exposure was seen at $6^{\text {th }}$ week postoperative follow up. The vaginal angles appeared lifted. 
None of the patient in the study group had post-operative nausea, vomiting, abdominal pain, vaginal discharge or secondary haemorrhage in the follow up schedule up to 6 months (Table 3 ).

Table 1. Demography of patients of TLH total no. 30 .

\begin{tabular}{|c|c|c|c|}
\hline \multicolumn{4}{|c|}{ Total numbers of patient-30 } \\
\hline Variable & Categories & Mean $\pm S D$ & Numbers (\%) \\
\hline Age & & $47.91 \pm 8.96$ & \\
\hline BMI & & $28.14 \pm 3.92$ & \\
\hline \multirow{2}{*}{ Comorbidity } & Absent & & $10(33.33 \%)$ \\
\hline & Present & & $20(66.66 \%)$ \\
\hline \multirow{3}{*}{ Diagnosis } & Malignant & & $1(3.33 \%)$ \\
\hline & & & \\
\hline & Benign & & $29(96.67 \%)$ \\
\hline
\end{tabular}

Table 2. Details of barbed sutures placed at vaginal vault.

\begin{tabular}{|c|c|c|c|}
\hline $\begin{array}{l}\text { Observation of suture line } \\
\text { at vaginal vault }\end{array}$ & Result & $\mathrm{No} / \%$ & Mean SD \\
\hline & No & $7(23.33 \%)$ & \\
\hline \multicolumn{4}{|l|}{ Exposure of suture at vault } \\
\hline & Yes & $23(76.67 \%)$ & \\
\hline Average number of suture exposures (times) & Number of exposures & & $1.57 \pm 1.20$ \\
\hline \multirow[t]{2}{*}{ Average length of suture exposure (mm) } & Suture length & & $2.64 \pm 1.65$ \\
\hline & Yes & $5(16.67 \%)$ & \\
\hline \multicolumn{4}{|l|}{ Requirement of Hemostasis } \\
\hline & No & $25(83.33 \%)$ & \\
\hline \multirow{2}{*}{$\begin{array}{l}\text { Exposure of barbed suture at vaginal vault on } \\
\text { per speculum examination-in immediate } \\
\text { post-operative period }\end{array}$} & Yes & $2(6.67 \%)$ & \\
\hline & No & $28(93.33 \%)$ & \\
\hline
\end{tabular}

Table 3. Follow up to day 8, 2 and 6 months (Post-operative period).

\begin{tabular}{ccccc}
\hline Observations & & $\begin{array}{c}\text { Day } 8 \\
\text { No/\% }\end{array}$ & $\begin{array}{c}2 \text { Months } \\
\text { No/\% }\end{array}$ & $\begin{array}{c}6 \text { Months } \\
\text { No/\% }\end{array}$ \\
\hline $\begin{array}{c}\text { Exposure of barbed suture } \\
\text { at vaginal vault }\end{array}$ & Yes & $0(0 \%)$ & $0(0 \%)$ & $0(0 \%)$ \\
& No & $30(100 \%)$ & $30(100 \%)$ & $30(100 \%)$ \\
\hline $\begin{array}{c}\text { Nausea/Vomiting/Abdominal pain } \\
\text { Vaginal discharge, Secondary }\end{array}$ & No & $0(0 \%)$ & $0(0 \%)$ & $30(100 \%)$ \\
\hline haemorrhage & Yes & $0(0 \%)$ & $0(0 \%)$ & $0(0 \%)$ \\
& No & $30(100 \%)$ & $30(100 \%)$ & $30(100 \%)$ \\
\hline
\end{tabular}




\section{Discussion}

Barbed suture has been used for vaginal vault closure increasingly since 2011. The majority published literature lacks the proper description of suturing method with the use of barbed suture [3] [4] [7]. While some publications have described them well [8] [9].

The published studies comparing the results of use of barbed sutures and polygalactin 910 used for vaginal vault closure have not reported the difference in post-operative outcome [4] [10].

Use of barbed suture does not increase morbidity, in fact it reduces the time of surgery and does not increase vaginal vault related complications like vault dehiscence [11]. But there are reports of small bowel obstruction because of adherent loop or mesentery at vaginal vault [12] [13]. There have also been suggestion of covering the suture line by adhesion barrier or closure of peritoneum above it when barbed suture is used for vaginal vault closure to avoid this complication [5] [8] [14] [15].

To remove apprehension related to exposure of barbed suture and related complications, this prospective study of 30 patients quantifies length of barbed suture exposed at vaginal vault using one uniform technique and assess postoperative risk of adhesions and sequalae as abdominal pain and bowel obstruction.

A new uniform method of vaginal vault closure was used also aimed at reducing the risk of suture exposure at the vaginal vault, provide haemostasis and support vaginal vault. The method may be termed as DS method of vaginal vault closure.

Observation of suture line at vaginal vault had shown interesting results. The appropriate tension applied while pulling the suture causes soft tissue compression. At this place suture was buried or small portion of suture was visible. This visible suture also was below the adjacent surface reducing possibility soft tissue entanglement.

At present no published data mentions amount of barbed suture exposed at vaginal vault and risk of post-operative adhesion, pain, or bowel obstruction.

In the present study of 30 cases the number of sutures placed over the vaginal vault was 5 or 6 and mean exposure of length of suture was only $2.64 \pm 1.65 \mathrm{~mm}$. The suture was exposed at vaginal vault at $1.57 \pm 1.20$ places. This explains very minimal suture exposure and at $<2$ places only. In one patient suture exposed at 5 places. Building optimum tension causes suture burial or to be depressed below the surface of the tissue sutured.

These observations would favor reducing the complications related to suture exposure. No patient in the present study had any complications.

Mean number of sutures placed at vaginal vault were also less in this study as compared to others who have reported double layer closure [16]. Some authors have suggested placement of suture too close as $5 \mathrm{~mm}$ [17]. This results in placing more number of sutures at vault. In the present study the sutures were taken $8 \mathrm{~mm}$ to $1 \mathrm{~cm}$ apart.

Including uterosacral ligaments, fixing macendrots ligaments to vaginal angles and approximating pubocervicovesical fascia and pre rectal fascia over the vault 
provides desired support to the vaginal vault.

We believe optimum tension on the suture line and placing a less number of sutures would reduce barbed suture exposure at vaginal vault irrespective of technique of suturing.

The new technique of vaginal closure may be named as DS technique.

Limitations-This is prospective study quantifies suture exposure using a new method. The exposure of barbed suture at vaginal vault may change depending on a different method used. More number of patients may be required to be prospectively evaluated to standardize and adopt this new DS suturing technique.

\section{Conclusion and Recommendations}

The study with an accepted relative error of $5 \%$ quantifies barbed suture exposure at vaginal vault. We had adopted a uniform new method to study and quantify barbed suture exposure. With this DS method, it was observed that minimal portion of suture was exposed, and it was only at one or 2 places at vaginal vault. Decreasing suture exposure at vaginal vault will reduce exposure related risk. Methods of suturing vagina by use of barbed suture should also aim at reducing suture exposure. This would reduce post-operative risk of adhesion at vaginal vault and bowel obstruction. In the present study none had immediate or delayed complications.

\section{Acknowledgements}

I am Thankful to Dr. Nira Soni for assisting in compiling data necessary for the study.

\section{Conflicts of Interest}

The authors declare no conflicts of interest regarding the publication of this paper.

\section{References}

[1] Greenberg, J.A. (2010) The Use of Barbed Sutures in Obstetrics and Gynecology. Reviews in Obstetrics and Gynecology, 3, 82-91.

[2] Greenberg, J.A. and Clark, R.M. (2009) Advances in Suture Material for Obstetric and Gynecologic Surgery. Reviews in Obstetrics and Gynecology, 2, 146-158.

[3] Roda, J.L.H., Llueca, A.J.A., Maazouzi, Y., et al. (2015) The Use of Barbed Suture for Vaginal Cuff Closure in Total Laparoscopic Hysterectomy. Obstetrics \& Gynecology International Journal, 3, 00088. https://doi.org/10.15406/ogij.2015.03.00088

[4] López, C.C., De Los Ríos, J.F., González, Y., Castañeda, J.D., Almanza, L.A., Jiménez, L.A., et al. (2019) Barbed Suture versus Conventional Suture for Vaginal Cuff Closure in Total Laparoscopic Hysterectomy: Randomized Controlled Clinical Trial. Journal of Minimally Invasive Gynecology, 26, 1104-1109. https://doi.org/10.1016/j.jmig.2018.08.030

[5] Lee, E.T.C. and Wong, F.W.S. (2015) Small Bowel Obstruction from Barbed Suture Following Laparoscopic Myomectomy-A Case Report. International Journal of Surgery Case Reports, 16, 146-149. https://doi.org/10.1016/j.ijscr.2015.09.039 
[6] Clapp, B., Klingsporn, W., Lodeiro, C., Wicker, E., Christensen, L., Jones, R. and Tyroch, A. (2020) Small Bowel Obstructions Following the Use of Barbed Suture: A Review of the Literature and Analysis of the MAUDE Database. Surgical Endoscopy, 34, 1261-1269. https://doi.org/10.1007/s00464-019-06890-Z

[7] Nawfal, A.K., Eisenstein, D., Theoharis, E., Dahlman, M. and Wegienka, G. (2012) Vaginal Cuff Closure during Robotic-Assisted Total Laparoscopic Hysterectomy: Comparing Vicryl to Barbed Sutures. Journal of the Society of Laparoendoscopic Surgeons, 16, 525-529. https://doi.org/10.4293/108680812X13462882736772

[8] O’Hanlan, K.A., Emeney, P.L., Peters, A., et al. (2016) Analysis of a Standardized Technique for Laparoscopic Cuff Closure following 1924 Total Laparoscopic Hysterectomies. Minimally Invasive Surgery, 2016, Article ID: 1372685.

https://doi.org/10.1155/2016/1372685

[9] Blikkendaal, M.D., Twijnstra, A.R.H., Pacquee, S.C.L., Rhemrev, J.P.T., Smeets, M.J.G.H., de Kroon, C.D. and Jansen, F.W. (2012) Vaginal Cuff Dehiscence in Laparoscopic Hysterectomy: Influence of Various Suturing Methods of the Vaginal Vault. Gynecological Surgery, 9, 393-400.

https://doi.org/10.1007/s10397-012-0745-5

[10] Morgan-Ortiz, F., Contreras-Soto, J., Soto-Pineda, J. and López-Zepeda, M. (2012) Comparison of Unidirectional Barbed Suture and Polyglactin 910 Suture in the Vaginal Vault Closure in Patients Undergoing Total Laparoscopic Hysterectomy. Journal of Minimally Invasive Gynecology, 19, S152-S153.

https://doi.org/10.1016/j.jmig.2012.08.420

[11] Karacan, T., et al. (2018) Comparison of Barbed Unidirectional Suture with Figure-of-Eight Standard Sutures in Vaginal Cuff Closure in Total Laparoscopic Hysterectomy. Journal of Obstetrics and Gynaecology (Lahore), 38, 842-847. https://doi.org/10.1080/01443615.2017.1416597

[12] Donnellan, N.M. and Mansuria, S.M. (2011) Small Bowel Obstruction Resulting from Laparoscopic Vaginal Cuff Closure with a Barbed Suture. Journal of Minimally Invasive Gynecology, 18, 528-530. https://doi.org/10.1016/j.jmig.2011.03.011

[13] Chen, H., Hong, M.-K. and Ding, D.-C. (2017) Acute Small Bowel Obstruction Caused by Barbed Suture on the Second Day after Laparoscopic Hysterosacropexy: A Case Report and Literature Review. Taiwanese Journal of Obstetrics and Gynecology, 56, 247-249. https://doi.org/10.1016/j.tjog.2016.03.008

[14] Bogliolo, S., Musacchi, V., Dominoni, M., Cassani, C., Gaggero, C.R., De Silvestri, A., et al. (2015) Barbed Suture in Minimally Invasive Hysterectomy: A Systematic Review and Meta-Analysis. Archives of Gynecology and Obstetrics, 292, 489-497. https://doi.org/10.1007/s00404-015-3653-x

[15] Gilbert, A., Abo-Alhassan, F., Ortega-Deballon, P., Cheynel, N., Rat, P. and Facy, O. (2019) Peritoneal Closure Using Self-Anchoring-Barbed Absorbable Sutures during Laparoscopic Transabdominal Preperitoneal Inguinal Hernioplasty: How to Make It More Safe? International Journal of Abdominal Wall and Hernia Surgery, 2, 7-11. https://doi.org/10.4103/ijawhs.ijawhs_30_18

[16] Kim, J.H., et al. (2016) Barbed versus Conventional 2-Layer Continuous Running Sutures for Laparoscopic Vaginal Cuff Closure. Medicine (Baltimore), 95, e4981. https://doi.org/10.1097/MD.0000000000004981

[17] Uccella, S., Ghezzi, F., Mariani, A., et al. (2011) Vaginal Cuff Closure after Minimally Invasive Hysterectomy: Our Experience and Systematic Review of the Literature. American Journal of Obstetrics \& Gynecology, 205, 119.e1-119.e12. https://doi.org/10.1016/j.ajog.2011.03.024 